\title{
Interactive First-year Engineering Seminar Series
}

\author{
Jason Bazylak \\ Lecturer, Mechanical and Industrial \\ Engineering \\ University of Toronto \\ jbazylak@mie.utoronto.ca
}

\author{
Susan McCahan, Ph.D., P.Eng. \\ Associate Professor, Mechanical and Industrial \\ Engineering \\ University of Toronto \\ mccahan@mie.utoronto.ca
}

\begin{abstract}
Six years ago, a Seminar Series was implemented in the Engineering Strategies and Practice course for first-year engineering at the University of Toronto. The learning objectives of the seminar series are to teach students communication as an engineer, independent learning, and systems thinking. Additionally the seminar series creates a forum for faculty, and other professional mentors, to imbue a passion for learning in a more intimate environment than is normally associated with first-year courses. The interactive seminar series has proven popular with both the students and the 40+ volunteer seminar leaders recruited from academia, industry, the local community, and non-profit organizations. These seminar leaders mentor their students through a discussion of the technical, social, environmental, economic, legal, ethical, political, and/or human factors associated with an engineering-related topic of the seminar leader's choosing. The past, present, and future of the seminar series will be discussed in this paper. By measure of self-reported growth the learning objectives are being met and as such the seminar series is considered a success. It is predicted to continue, with goals of continuous improvement, for years to come.
\end{abstract}

\section{Introduction}

Educators of undergraduate students share a common list of challenges in the quest to improve the student experience and student learning. The Boyer report [1] made several recommendations on the improvement of the undergraduate engineering experience. One of these recommendations is the inclusion of a freshmen seminar series in the first-year of study. These seminars are to be small in size, but big in excitement. The seminars are a forum for faculty to imbue a passion for learning in a more intimate environment than is normally associated with first-year courses. The Engineering Strategies and Practice (ESP) seminar series is our attempt to meet this need. Before describing the ESP seminar series we need to introduce ESP itself.

\subsection{What Is ESP?}

ESP is a two course series in design and communication that is required of first-year engineering students in eight of nine disciplines offered at the University of Toronto. The first course runs during the fall term (Sep - Dec) and the second course runs in the spring term (Jan - Apr). ESP just finished its sixth year of operation, two in pilot mode and four in full implementation. The course is taught by a large and diverse teaching team consisting of 30 teaching assistants, 5 lecturers, 5 communications instructors, 15 project managers, a seminar coordinator, a projects coordinator, a course coordinator, and two fulltime administrative staff. The authors of this paper have collectively served ESP in four of these eight roles, and one author has been with the course since its initial planning stage.

Students have five hours per week of contact time with the teaching team. Three hours are spent in the lecture hall learning from one of our five experienced lecturers. The final two hours are spent in the tutorial room either working on their design project or in an interactive discussion seminar. While working on their design project they are under the supervision of a highly trained teaching assistant. During this time, they are able to get advice from a specialized communications instructor, and in the second term they report their project status to a faculty project manager. While in the discussion seminars the students are facilitated by a volunteer seminar leader recruited from industry, academia, or the local community and non-profit organizations. 
In the first term lectures, students are instructed on a design process, team work and leadership, communicating as an engineer, and the broader implications of an engineer's role in society and the environment.

In the first term tutorials, students are grouped into teams of six and tasked to design a solution for a fictitious, but realistic design problem. In 2008 students were challenged to design a collection system for Home Depot customers to drop off their CFL bulbs for recycling. In 2009 students redesigned the iconic ring-and-post bicycle stands for the city of Toronto.

We refer to this as the "design with training wheels" stage. All teams are working on the same project allowing them to consult with one another and understand what is being expected of them. This increases their confidence in a situation which is unnerving for many student not used to unconstrained assignments. Additionally since the course instructors are the clients, students do not have to worry about the client contact stage and instead can focus their efforts on the design process, honing their communication skills, and dealing with team dynamics issues.

An important side note is that our experience with ESP has taught us not to underestimate the effort that students will expend dealing with team dynamics. High achieving students are commonly concerned that their final grade depends heavily on their teammates, as almost half of the course work is a team grade. The team dynamics lectures were not originally part of the course, but were added after realizing that our students were not as naturally proficient with team work as we had planned for in the original course design.

In the second term the training wheels come off, and the students work on group-unique design problems for external clients; however a detailed description of the second term of ESP is beyond the scope of this paper. Instead we will be discussing the interactive discussion seminars conducted in tutorial in more detail.

\subsection{What Is The Seminar Series?}

By the final three tutorials of the first term the students have completed their design projects and are reassigned to seminar sessions. These seminar sessions match up 40+ enthusiastic volunteer seminar leaders from industry, academia, the local community, or nonprofit organizations, with groups of approximately 20 students. These seminar leaders facilitate a student discussion on an engineering-related topic that has some debatable aspect surrounding it. This aspect is usually tied to the broader design considerations which they are learning in lecture including: societal, environmental, economic, legal, ethical, political, and/or human factors. Examples of past topics include: "Nuclear power: Good or bad" and "Application of sewage biosolids on agricultural land: Is it safe?"

It is important to note that the role of the seminar leader is not to instruct, but rather to facilitate. In a well-run seminar session, the seminar leader will spend little time addressing the class as a whole. Instead the students will be the primary voices heard, with the seminar leader speaking up only to ask thought provoking questions or to bring the discussion back on topic.

The students meet for two-hours per week over three weeks for a total of six hours of contact time. Approximately $1 \frac{1 / 2}{2}$ hours of this time is taken up by student presentations (see below), with the remaining $4 \frac{1}{2}$ hours left for discussions and activities.

The exact structure of the seminars varies from seminar leader to seminar leader, but one common factor is that each student is expected to make an informal three minute presentation to their seminar leader and their peers. In this presentation they are to show an understanding of some aspect of the seminar topic and to clearly communicate their educated opinion on the matter. For some of our students, particularly our English-as-a-Second-Language students, simply speaking in front of an audience is a daunting task. Even for our native-English speaking students with public speaking experience, it can be daunting to take a stance and justify their arguments in a debate.

The seminars are a graded aspect of the course with $4 \%$ of the final course grade being derived from the student's attendance and participation (60\%) and their oral presentation (40\%).

\section{Past}

Now that you are familiar with the current incarnation of ESP and its seminar series, it is good to understand the motivation behind the course and therefore the seminar series. To do this we have to look a few years beck to the creation of the course series.

\subsection{Why Was ESP Created?}

ESP was designed to educate our students in learning objectives that, though equally important as technical competencies, are often not formally taught in engineering programs. These learning objectives include:

- Communication

- Problem solving

- Independent learning 


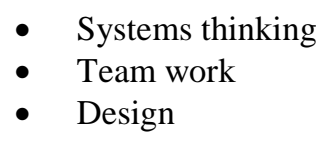

At the time some of these learning objectives were not taught at all, and those that were taught were not taught within the context of engineering. For example we had a communications course, but it was a standalone technical communications course taught using fictitious examples, entirely segregated from the rest of the courses.

This list of learning objectives was identified by a University of Toronto decanal task force from many sources including the Boyer report [1] and the Accreditation Board for Engineering and Technology's (ABET) outcomes criteria [2]. Even six years later these objectives are still valid considering their close correlation with the newly devised graduate outcomes of the Canadian Engineering Accreditation Board (CEAB) [3].

\subsection{Why Were The Seminars Created?}

The seminars portion of the course was designed to address several of these learning objectives including: communications, independent learning, and systems thinking.

Outside these learning objectives is the suggestion of the Boyer report that getting students excited about engineering is also important. In their first term, students bounce from large lecture hall to large lecture hall, and are in danger of not receiving any personal contact with professional mentors beyond their teaching assistants. In the small seminar sessions students are able to get this personal contact. Serendipitously seminar leaders who take the time to volunteer for this role tend to be those with a passion for the profession, and often make the best professional mentors.

Finally it was not known at the time of their creation, but the seminars also tie in nicely with the CEAB graduate outcome of having engineering graduates knowledgeable of the impact of engineering on society and the environment [3].

\section{Present}

Now that you have a background in the seminar series let us come back to the present and investigate how the seminar series is being received by those who are most closely involved with it, the students and the seminar leaders.

\subsection{What Do The Students Think About The Seminar Series?}

In 2008, a comprehensive 50 question online survey was conducted for students who had just completed their seminars. We received 386 responses out of an enrolled 839 students for a useable response rate of $43 \%$. This is a high response rate for an optional online survey.

Student opinion of the seminars was overwhelmingly positive. They felt challenged and encouraged and believed there to be strong engineering content in their seminars. Almost $90 \%$ of respondents stated that they attended all seminars. $70 \%$ indicated that they had completed all the required readings; however this was contrary to the anecdotal evidence given by seminar leaders. The seminar leaders, topics, and seminar sessions received excellent reviews. Students enjoyed the seminars and felt that they were valuable to their growth as engineers. Almost $75 \%$ agreed that the seminars should continue next year.

In addition to the multiple choice responses, students gave four long answer responses. From these responses nine themes were identified. Below are the themes along with an example student comment.

1) The seminars promoted meeting new people.

2) The students would have preferred to select their own seminar topic.

3) The students felt that the seminars linked their theoretical studies with the "real world".

4) The students had a positive experience with their Seminar Leader.

5) The students found the seminars comfortable and welcoming.

6) The students wanted more structure and explicitly stated expectations.

7) The students were enlightened by the seminar experience.

8) Many students had difficulties with oral communication, but agreed that the seminars helped develop those skills despite the difficulties.

9) The students weren't able to dedicate the effort they would have liked to the seminars due to high work load. 


\subsection{What Do The Seminar Leaders Think About The Seminar Series?}

In 2008, at the same time as the student survey, a survey was conducted of the 43 seminar leaders. 30 survey responses were received giving a response rate of approximately $70 \%$.

The findings of the multiple choice portion of the survey were that the majority of seminar leaders had an engineering background. They worked primarily in academia with a small but significant number working in industry. They generally felt that there was a good level of communication with the teaching team. They also felt well supported. The seminar leader luncheon, a training event, was attended by less than half of the seminar leaders; however amongst those that did attend the value of the luncheon was viewed positively. Overall seminar leaders had a strongly positive experience in the seminars and the majority would serve as seminar leaders next year if their schedules permit it.

The answers to the 11 long answer questions were analyzed, and eight themes or suggestions were identified. These are listed below along with an example seminar leader comment.

1) The seminar leaders saw the students growing as engineers.

2) The seminar leaders found it difficult to motivate the students.

3) The requirement to complete the assigned readings needs to be stressed to the students.

4) The students need training on making presentations prior to the seminars.

5) The students didn't understand the importance / relevance of the seminars to the course.
6) The student evaluation process was difficult to execute.

7) The seminar leaders thought it worked well to...

...use a debate format for presentations.

...use Think - Pair - Share.

...have students grade each other's presentations.

...assign students to initiate discussions.

...assign independent research.

...summarize the main points of the assigned readings.

8) The seminar leaders thought it would have been useful if...

...they had an email list to contact the students.

...they had known course logistics policies.

...the rooms were equipped with flip charts, markers, and data projectors.

...resources could be shared between seminars.

\subsection{Is The Seminar Series Meeting The Intended Learning Objectives?}

It is difficult to accurately measure absolute growth in skills such as communication, independent learning, and systems thinking. The method we used was student self-reported growth data collected via the optional online survey discussed above. Students were asked to identify their perceived growth rate in a list of abilities on a scale of "No Growth - Slight - Moderate - Substantial - Exceptional”. The majority of students consistently identified moderate to substantial growth in all the identified abilities (see table 1). Table 1 also links the abilities listed in the survey to the learning objectives identified for the seminar series.

Table 1 - Percentage of students who percieved their growth to be moderate to substantial

\begin{tabular}{|l|c|c|}
\hline \multicolumn{1}{|c|}{ Ability to... } & Students (\%) & Learning Objectives \\
\hline $\begin{array}{l}\text { identify, understand and explain the importance of... to a } \\
\text { practicing engineer }\end{array}$ & & \\
\hline ...environmental issues... & 60.7 & Systems Thinking \\
\hline ...economic issues... & 65.2 & Systems Thinking \\
\hline ... social and human factors... & 66.6 & Systems Thinking \\
\hline ...legal requirements... & 51.0 & Systems Thinking \\
\hline $\begin{array}{l}\text { identify stakeholders and their key objectives within an } \\
\text { engineering project }\end{array}$ & 61.8 & Systems Thinking \\
\hline read a publication objectively and identify the critical arguments & 67.1 & Systems Thinking \\
\hline construct a credible argument & 61.5 & Independent Learning \\
\hline give a presentation that is professional in tone and substance & 59.7 & Communication \\
\hline
\end{tabular}




\section{Future}

Using the survey data and anecdotal evidence we have identified a number of items that seem to be working, and other items that need improvement.

\subsection{What Is Working Well?}

The seminars are appealing to the students. They consistently indicate through surveys that the seminars are their favourite part of ESP. We appear to be succeeding in generating the excitement in our first-year students for which the Boyer report calls.

Seminar leaders enjoy the experience of working with the students. They enjoy the flexibility that they are given to explore engineering issues that are of particular interest to them. Finally they enjoy being involved in the professional growth of a class of future engineers.

A major benefit of recruiting seminar leaders from broad walks of life has been that each seminar leader brings a bit of him or herself into their seminar discussions. Whether the seminar leader is a commuter who has to fight his way through the traffic on the poorly designed Gardiner expressway each and every morning, to the academic who grew up in the Regent Park projects and faced the ill conceived social engineering experiment in every aspect of her personal life, each brings valuable experience to their seminars that cannot be underestimated.

\subsection{What Do We Need To Improve?}

It is a major undertaking each year to recruit at least 40 seminar leaders in order to keep the size of the seminar groups down to a number manageable for a discussion seminar, approximately 20 students. Luckily, as discussed, previously serving as a seminar leader is a positive experience for our volunteers, and as such we have a dedicated group of former seminar leaders willing to return.

Unfortunately the requirement to spend six hours in the middle of the work week, in the middle of the day, can be challenging for even the most dedicated supporter. Therefore for any given year we have approximately 20 seminar leaders who need to be replaced.

One solution has been the creation of optional evening seminars. These seminars take place outside of the normal tutorial times. Any students interested in attending the evening seminars instead of their daytime seminar may volunteer to do so. As of this year we have run three optional evening seminars and they were all completely full and well reviewed. We implemented this in order to accommodate a couple of our seminar leaders from industry who were keenly interested in participating, however could not get away from work during regular seminar times. This has been a successful experiment, and we will continue at this level; however it does not entirely solve our seminar leader recruitment issue.

One obstacle new seminar leaders face, and therefore is an obstacle for our recruitment efforts, is the time required for the creation of a new seminar, including structure, activities and readings selection. This preparation time varies with the experience of the seminar leader, but we estimate it takes 6 to 10 hours to create a seminar from scratch. For many, this is a daunting task to be taken on as a volunteer role, and it is a deciding factor in their decision not to participate.

The solution we have proposed and are beginning to implement is the creation of a seminar research guide. The 2009 guide contains links to databases of electronic books, journals, newspapers, and magazines from which the seminar leader could easily locate reading materials to assign to their students. In the future we plan to expand this research guide to also contain example seminars with both completed and simple templates.

While having a completed seminar to step into would be the easiest for a seminar leader, it does work against a number of the benefits of the seminars. For example one major benefit has been that each seminar leader brings a topic that is of particular interest to him or her. This passion for the topic is something that is difficult to recreate with a "canned" seminar. However since there are often last minute scrambles, this will be kept as a last resort.

More appealing is the creation of example templates, with ready planned structure and activities, into which our new seminar leaders can insert their own topic and readings. Our experience with these seminars has taught us that there are several different formats that tend to work for our students. For example, using assigned two-person oral debates in place of pre-prepared three minute presentations has been highly praised by both seminar leaders and students.

As our seminar research guide grows into a complete repository, the hope is that more potential seminar leaders will feel comfortable joining the ESP team. 


\subsection{What Is On Our Wish List?}

The Access Copyright agreement gives educators permission to make photocopies of copyrighted material for use in the classroom. This enlightened agreement allows educators to make use of a wider range of sources then would otherwise be possible. It allows us to hand out photocopies of an article detailing a current event from the local newspaper, or copies of example problems from a book other than the course text. This agreement is a powerful teaching tool.

Unfortunately the Access Copyright agreement has not kept up with developing technologies, particularly document digitization. Therefore, our seminar leaders are legally allowed to make photocopies of a magazine article for their students, but they are not allowed to electronically scan the article and post it on the course website. This has had a particularly stifling impact on the seminars, as we deal with hundreds of articles, book chapters, and other publications each year.

We are currently dealing with this issue by attempting to get author permission, finding substitute articles in the electronic collection of our library, or attempting a complicated hardcopy distribution. The ideal solution would be a Digital Access Copyright agreement.

\section{Conclusion}

Communication, independent learning, and systems thinking have been identified by key players in the engineering profession as required skills for our future engineers. The ESP seminar series borrows an instructional method long-used in the humanities to educate our students in these skills. The students learn to critically read materials from a wide range of sources. They learn to absorb information both from those readings and orally from their peers. Finally they practice using their engineering judgment to formulate an opinion and to express that opinion succinctly to an audience. This is all done in an environment of free thinking that is enjoyable for the students and encourages them to continue on as engineers.
On a deeper level the ESP seminar series teaches our students to care about things that do not necessarily fit into our equations. Engineers often get criticized for taking a mechanistic view of the world, of neglecting the people living in our well-defined world of mathematics and physics. These seminars are an introduction of a humanistic view of the world to our students. We teach them that they must be aware of the concerns of the stakeholders outside their clients and users. They do not necessarily have to adapt their designs to meet these concerns, as there are times when solid engineering reasons justify why these concerns cannot be met. However, the students learn that engineers cannot simply ignore these concerns.

\section{Acknowledgements}

We would like to acknowledge the dedicated contributions of the founding members of the ESP Teaching Team and all the team members who have come and gone since. They have all left their mark on this course, and it is all the better for it.

\section{References}

[1] The Boyer Commission on Educating Undergraduates in the Research University, "Reinventing Undergraduate Education: a blueprint for America's research universities," Boyer, 1998. [Online]. Available:

http://naples.cc.sunysb.edu/Pres/boyer.nsf/. [Accessed: 17May-2010].

[2] Engineering Accreditation Commission, "Criteria for accrediting engineering programs,” ABET, 2010-2011 accreditation cycle, 27-Jan-2010. [Online]. Available: http://www.abet.org/Linked\%20DocumentsUPDATE/Criteria\%20and\%20PP/E001\%201011\%20EAC\%20Criteria\%201-27-10.pdf. [Accessed: 17May-2010].

[3] Canadian Engineering Accreditation Board, "2009 Accreditation Criteria and Procedures,” Engineers Canada, 2009. [Online]. Available:

http://www.engineerscanada.ca/e/files/Accreditation Criteri a_Procedures_2009.pdf. [Accessed: 17-May-2010]. 